\title{
An epidemiologic survey of the trend of accidents and injuries in Kurdistan province between 2010 and 2014
}

\author{
Afkhamzadeh $A^{1}$, Vaisi Khodlan $N^{2}$, Rahmani $K^{3}$, Resaeian $S^{4}$, Mostafavi $M^{2}$, Vahabizad $F^{5}$, $\operatorname{Rasouli} M^{6}$ \\ 1. Associate Professor of Community of Medicine, Social Determinants of Health Research Center, Research Institute for \\ Health Development, Kurdistan University of Medical Sciences, Sanandaj, Iran. \\ 2. Msc of Epidemiology, Group Control Diseases Communicable, Vice Chancellor for Health Affairs, Kurdistan University \\ of Medical Sciences, Sanandaj, Iran. \\ 3. Assistant Professor of Epidemiology, Social Determinants of Health Research Center, Research Institute for Health \\ Development, Kurdistan University of Medical Sciences, Sanandaj, Iran. \\ 4. Bachelor of Public Health, Group Control Diseases Communicable, Vice Chancellor for Health Affairs, Kurdistan \\ University of Medical Sciences, Sanandaj, Iran. \\ 5. Medical Student, Student Research Committee, Kurdistan University of Medical Sciences, Sanandaj, Iran. \\ 6. MSc of Epidemiology, Vice Chancellor for Educational and Research, Kowsar Hospital, Kurdistan University of Medical \\ Sciences, Sanandaj, Iran (Correspondence Author), Tel: +98-8733611250, E-mail: rasouli1010@ gmail.com
}

\begin{abstract}
Background and Aim: Accidents and injuries are among the main causes of disability and mortality and are regarded as public health problems. Considering the importance of this subject, the aim of this study was to investigate the incidence and trend of accidents and injuries in Kurdistan Province.

Materials and Methods: This cross-sectional study was conducted in Kurdistan Province, between 2010 and 2014. Data were extracted from national road traffic, injuries and accident databases. Data analysis was performed by using Stata 12.

Results: The findings of this study showed that the highest incidence rates of accidents and injuries belonged to the individuals between 20 and 29 years of age, and was two times higher in men than in women. We found a decreasing trend in the incidence rates of accidents and injuries between 2010 and 2013, and an increasing trend in 2014. Also, trauma showed a significant decreasing trend from 2010 to 2014, while the number of burn cases increased by four times between 2013 and 2014. Moreover, we found a fourfold increase in the number of suicide cases between 2010 and 2013 with a decreasing trend in 2014.

Conclusion: Results of this study suggested that accident-related injuries were most prevalent among male young adults, and road traffic injuries had the greatest impact on these individuals. Thus, appropriate plans should be designed to decrease the prevalence of RTAs among young adults.
\end{abstract}

Keywords: Epidemiology, Accidents and Injuries, Trend, Kurdistan

Received: Oct 10, 2018 Accepted: Jan 2, 2019

How to cite the article: Afkhamzadeh A, Vaisi Khodlan N, Rahmani K, Resaeian S, Mostafavi M, Vahabizad F, Rasouli MA. An epidemiologic survey of the trend of accidents and injuries in Kurdistan province between 2010 and 2014. SJKU 2019;24(2):41-51. 


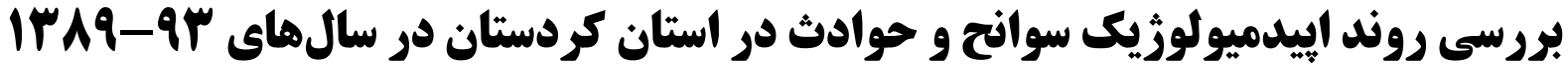

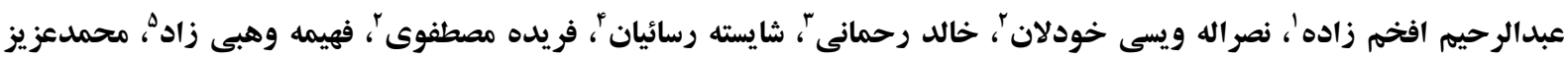
رسولى

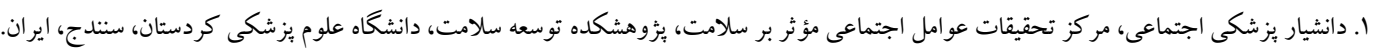

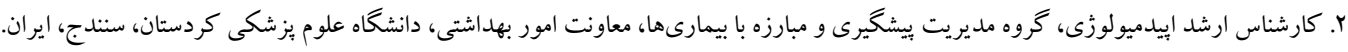

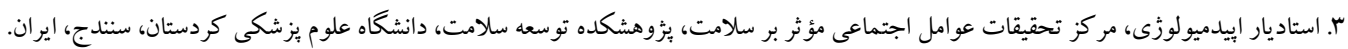

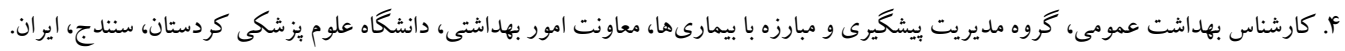

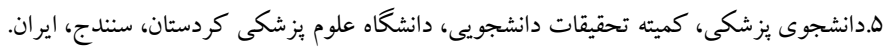

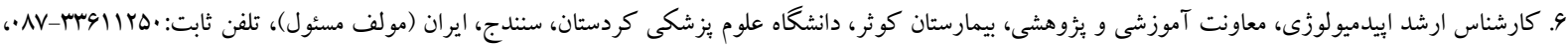

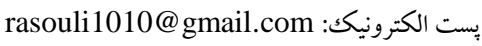

جـكيده زمينه و هدف: سوانح و حوادث يكى از علل اصلى ناتوانى و مرگك و مير شناخته شده و يكك مشكل بهداشت عمومى است. به دليل اهميت اين موضوع با هدف بررسى ميزان بروز و روند سوانح و حوادث در استان كردستان انجام شد. روش بروسى: در اين مطالعه مقطعى، دادههاى موردنياز شامل انواع مختلف سوانح و حوادث رخ داده در استان كردستان در سالهاى سه-9مسا از نرم افزار ثبت كشورى سوانح استخراج و مورد تجزيه تحليل قرار گرفت. بروز اختصاصى هر كدام از حوادث و روند زمانى رخداد اين حوادث در استان كردستان برحسب شهرستانها مورد بررسى قرار گرفت. آناليز داده ها با استفاده

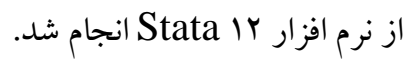
يافته ها: نتايج نشان داد بيشترين آمار حوادث در گروه سنى ·r تا جو سال و در مردان تقريباً دو برابر زنان بود. بررسى روند

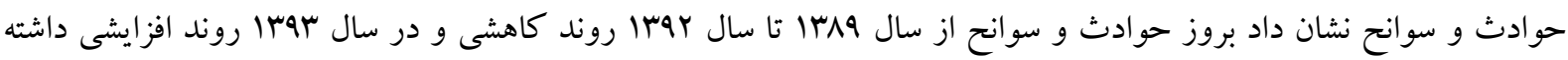
است. تعداد موارد ضربه، در اين بنج ساله روند كاهشى شديدى مشاهده گرديد و موارد سوختگى در سالهاى بوسا و سوسا

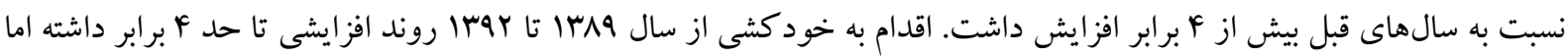
در سال سوبا كاهش يافت. نتيجه كيرى: بر اساس نتايج بهدست آمده از اين مطالعه مردان در دوره جوانى بيشترين مصدومان آسيبهاى ناشى از حوادث را تشكيل مىدهند و آسيبهاى ناشى از حوادث جادهاى بيشترين تأثير را بر روى اين گروه مى كذارد كه نيازمند برنامهريزى دستخاههاى مختلف در جهت كاهش اين حوادث در استان كردستان است. كليد وازه ها: ابيدميولوزى، سوانح و حوادث، روند، كردستان وصول مقاله :9V/V/IN اصلاحيه نهايى:9V/9/IV يذيرش:9V/I/IT 
شخصى از خودرو از علل ريشه اى آسيب هاى ترافيكى

محسوب مى شوند( • (961). از آنجاكه در استان كردستان جنين مطالعهاى صورت نخرفته و لزوم ييشخيرى از سوانح و حوادث در هر جامعهاى نيازمند اطلاعات مفيد و هدفمند است، لذا مطالعه حاضر با هدف بررسى روند ينج ساله رخداد انواع مختلف سوانح و حوادث

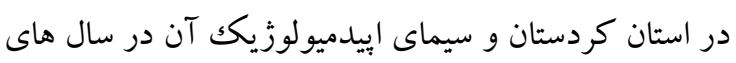

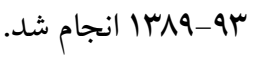

\section{روش بروسى}

مطالعه حاضر يكك بررسى مقطعى است كه به بررسى روند بروز انواع سوانح و حوادث در استان كردستان در طى

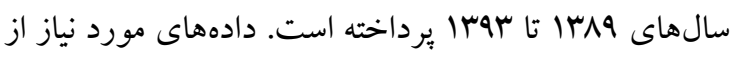
سيستم نرم افزارى مراقبت و ثبت سوانح و حوادث در سطح شهرستانهاى استان و از معاونت بهداشتى دانشگاه علوم يزشكى كردستان استخر اج شده است. استان كردستان يكى از اس استان ايران است كه در ناحيه شمال غربى ايران و در همسايخى كشور عراق قرار دارد. بر اساس سرشمارى سال هوبا، جمعيت استان كردستان حدود 19.4.... مىدهد. حدود 94\% جمعيت اين استان در مناطق شهرى و

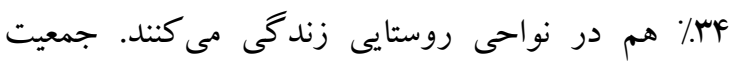
مورداستفاده در اين مطالعه شامل تمامى جمعيت تحت يوشش شهرى و روستايى شبكه بهداشت و درمان شهرستانهاى استان كردستان در سالهاى سو-9^ش| است كه از اطلاعات اين شبكه استخراج شده است و شامل 19.1111 نفر در هر دو جنس و به تفكيكك، جمعيت مردان NI IVVG حوادث ثبت شده در اين ه سال r ·ها|l مورد بود. در اين مطالعه روش نمونه گيرى تمامى موارد حوادث و سوانح گزارش شده به معاونت بهداشتى استان كردستان مورد بررسى قرار گرفت. در سيستم نرم افزارى ثبت سوانح در سطح استان، متغيرهاى مختلفى همجيون سن، جنس، شهرستان محل سكونت، منطقه رخداد حادثه (شهر يا روستا
طبق تعريف سازمان جهانى بهداشت، سانحه عبارت است از رويدادى بدون سابقه كه موجب آسيب قابلتشخيص مىشود و سانحه بهعنوان رويداد غيرمنتظره و برنامهريزى نشدهاى كه مىتواند منجر به آسيب شود تعريف مى گردد

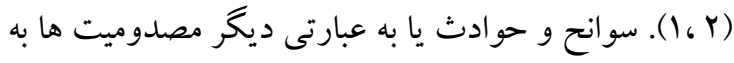
صورت كلى به دودسته آسيب هاى غيرعمدى و غيرعمدى تقسيمبندى مى گردد. حوادث غير عمدى عمدتاً شامل آسيبهاى ناشى از تصادفات جاده اى، مسموميت، سقوط، غرق شدكى و نظاير اينها است. حوادث غيرعمدى هم شامل آسيب به خود از جمله خودكشى و يا آسيب به ديخران از جمله خشونتهاى بين فردى، قتل و... است (r). افزايش حوادث و آسيبهاى گوناگون يكى از مهمترين خطرات تهديد كننده زندگى انسان ها در مناطق و كشورهاى مختلف جهان است كه سالانه باعث مرگك بيش از 9 ميليون نفر در جهان مى گردد (F). سوانح و حوادث در سراسر جهان به عنوان علت اصلى ناتوانى و مرگك و مير شناخته شده اند و يكك مشكل بهداشت عمومى در كشورهاى در حال توسعه و توسعه يافته محسوب مى شوند. صدمات ناشى . از حوادث تا سال ·.r.r.r دومين علت معلوليت در كشورهاى در حال توسعه و سومين علت مرگك و معلوليت در سراسر

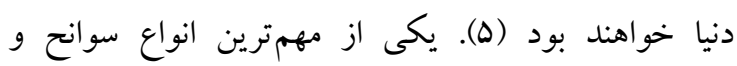
حوادث غيرعمدى سوانح ترافيكى است. سوانح ترافيكى در كشورهاى صنعتى شايعترين علت مرگك جوانان به شمار مىرود و در كشورهاى درحالتوسعه نيز هل درصد مركَها و ·ه درصد ناتوانىها ناشى از اين معضل است (9). بر اساس آمارهاى منتشر شده سازمان بزشكى قانونى كشور در سالهاى .وسا و |qه| در مجموع به ترتيب 91..ب و

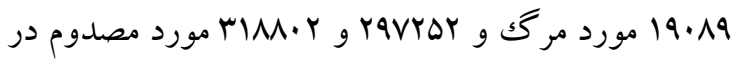
اثر حوادث ترافيكى در ايران وجود داشته است (N, V). افزايش رشد جمعيت، افزايش توليد و استفاده از وسايل نقليه، تغيير سبك زندگى افراد جامعه همراه با بالا رفتن تقاضاى خانوارها براى سفر و زياد شدن ميزان استفاده 
با ^^//س مورد در هر .... نفر بوده است. كمترين موارد

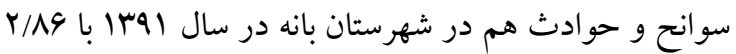
حادثه در هر . . . انفر گزارش گرديد (جدول (1). از نظر گروه هاى سنى فراوانى سوانح و حوادث در گروه

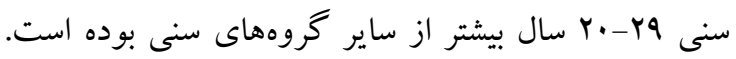
در اين بازه زمانى هاله، سوانح و حوادث در مردان (بيش از 9V \%) بيشتر از زنان اتفاق افتاده است. بيشتر موارد حادثه در محيطهاى شهرى اتفاق افتاده است. همجنين از نظر نوع حادثه بيشترين موارد سوانح، مربوط به حوادث ترافيكى و از بين آنها، تصادف خودرو بوده است. از طرف ديخر،

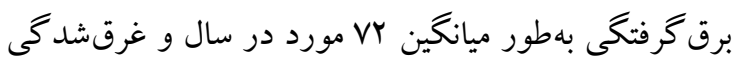
ميانخين سا مورد در سال كمترين موارد سوانح را به خود اختصاص داده است. از نظر محل وقوع حادثه، بيشترين فراوانى سوانح و حوادث به ترتيب در منزل، كو جهه، خيابان، بزر گراه و جاده رخ داده است (جدول Y). مقايسه روند زمانى رخداد سوانح و حوادث در طول اين دوره زمانى ه ساله نشان داد كه از سال هیrا تا بهبا روند كاهشى در تعداد رخداد حوادث در كل استان ديده مى شود اخرُجه در سال سوسا نسبت به سال قبل از آن اندكى افزايش داشته است. مقايسه شهرستان ها نشان مى دهد كه روند افزايشى وقوع حوادث و سوانح در شهرستان بيجار از سال •وسا و روند افزايشى در شهرستان سنندج از سال •وسا وجود دارد. در شهرستان كامياران از سال .وسا روند كاهشى خفيفى مشاهده مى گردد. در ساير شهرستانها همجنين نيز روند موارد سوانح و حوادث ديده مىشود

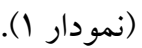

و يا خارج از شهر و روستا)، نوع حادثه (عابر بياده/ تصادف خودرو و موتورسوار/ سقوط/ ضربه/ حمله حيوانات/ مسموميت / برق گرفتگى / عقرب و مارگزيد گیى / سوختخى / خشونت/ خود كشى/ غرقشدگى و ساير حوادث)، زمان و مكان حادثه (منزل/ كوجه و خيابان/ بزرگراه و جاده/ مدرسه و مكان آموزشى/ محل كار/ اماكن ورزشى و تفريحى/ اماكن عمومى/ نامعلوم و ساير) ثبت گرديد. در مطالعه حاضر، دادههاى مورد نياز متناسب با اهداف مطالعه از نرم افزار كشورى استخراج و مورد بررسى قرار كرفت. در اين تحليل تمامى شهرستانهاى استان كردستان به عنوان منطقه و جمعيت در معرض خطر بر مبناى سرشمارى سال هوسا و ميانگين جمعيت- وزنى به ازاى ....1 شخصسال در نظر گرفته شده است. ميزان خام حادثه در طول Z

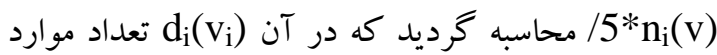
بروز حادثه در دوره ه ساله در شهرستان و V و جمعيت در معرض خطر در سال هوسا است. سيس روند زمانى رخداد سوانح و حوادث در استان كردستان برحسب شهرستانها و برحسب نوع حادثه با استفاده از شاخص ميزان بروز ترسيم كرديد. آناليز دادهها با براب استفاده از نرم افزار Stata نسخه r إ انجام شد.

يافته ها

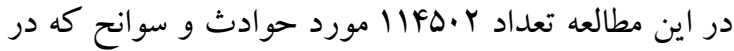
طى سالهاى بودند استخراج و آناليز شد. نتايج تحليل وقوع حادثه برحسب شهرستان و به تفكيك سال نشان داد كه بيشترين موارد سوانح و حوادث در شهرستان بيجار و در سال .وسا 


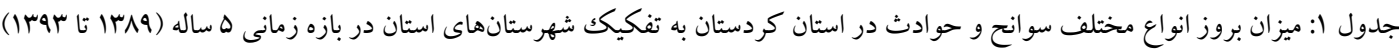

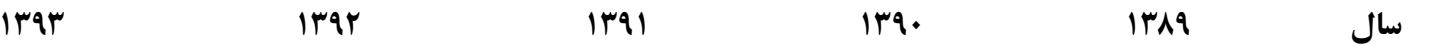

\begin{tabular}{|c|c|c|c|c|c|c|c|c|c|c|}
\hline فراوانى & بروز & فر اوانى & بروز & فر اوانى & بروز & فراوانى & بروز & فراوانى & بروز" & شهر \\
\hline$|r| \cdot \Lambda$ & rq/IF & 1.110 & $r \cdot / I V$ & $1 . k g F$ & $r \cdot / \wedge q$ & Q9YY & $19 / \mathrm{VA}$ & 1198. & $r r / A V$ & سنندج \\
\hline$r \cdot 1 \Delta$ & $Q / \%$. & rMlg & $1 \cdot / r Y$ & IVAr & $\mathrm{V} / \mathrm{AV}$ & IVDr & $V / V F$ & 1991 & V/rq & سقز \\
\hline $11 r 9$ & $\mathrm{~V} / \mathrm{IV}$ & $\Delta \Delta F$ & $r / 4 q$ & FaF & Y/AG & $0 . r$ & $r / l V$ & ar. & $r / q$. & بانه \\
\hline IIrr & $\Delta / V q$ & IVAY & $9 / 1 r$ & 1211 & $\Lambda / V q$ & rrov & $\mid r / \cdot V$ & YFFI & $1 Y / Q$ & مريوان \\
\hline lafF & Ir/A9 & 1490 & 1.199 & 1949 & $1 \pi / M$ & $r \cdot v r$ & $r \mid / 91$ & rArq & $r \cdot / r \Delta$ & قروه \\
\hline $1.1 \mathrm{~V}$ & $I r / V$ & 914 & $11 / 41$ & 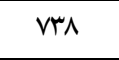 & $Q / Y r$ & qf. & $11 / V F$ & Avo & $1 \cdot / 9 r$ & ديو اندره \\
\hline rISV & YF/Y. & $r \cdot \wedge \Delta$ & rr/r/ & YMTY & $r q / 10$ & ras. & $\mu r / \cdot \Lambda$ & rVMr & $r \cdot 194$ & بيجار \\
\hline IYV. & $I Y / Y F$ & 1199 & $11 / 94$ & IFHA & $11 \% / 91$ & IFVr & $\mid F / Y Y$ & IFAT & $|F /| \mid$ & كامياران \\
\hline VEs & $11 / 90$ & gru & $9 / 99$ & 9.1 & $9 / \Gamma \wedge$ & - & - & - & - & دهگلان \\
\hline rFq.P & $\mid \Delta / T \varphi$ & 11.90 & $1 \pi / 10$ & rIfEY & $\| \pi / 4$. & TrDAY & $\mid f / \cdot r$ & PFDQq & $\mid \Delta / T r$ & كل \\
\hline
\end{tabular}

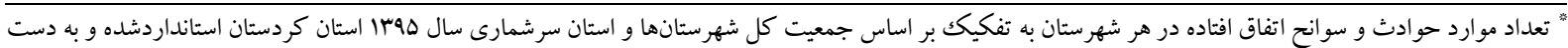

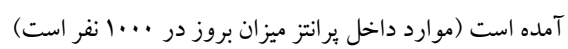

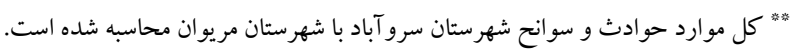

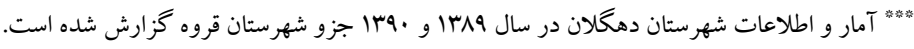

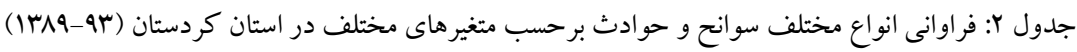

\begin{tabular}{|c|c|c|c|c|c|}
\hline (\%) & 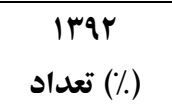 & 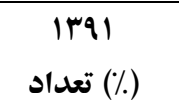 & 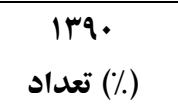 & $\begin{array}{c}1 \% 9 \\
1 \%(\%) ~\end{array}$ & ستغير \\
\hline $19 \Delta ৭(r q / F)$ & $\mid F G Y(Y \backslash / Q)$ & $r \cdot Q F(q / \Lambda)$ & rMg. $(1 \cdot / \Delta)$ & $\operatorname{rOFF}(1 \cdot / \Gamma)$ & كمتر از • ا سال سنى \\
\hline $499 \Delta(Y \cdot / r)$ & FGY (IN/r) & rVDV (IV/D) & ra9D (IV/9) & Frr/ (IV/9) & $1 \cdot-19$ \\
\hline$k 9.4(19 / 9)$ & $\Delta 91 V(Y \Lambda)$ & $V \cdot F r(Y Y / \Lambda)$ & VIrA (rI/G) & 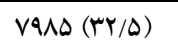 & $r \cdot-r q$ \\
\hline$r \Delta F \cdot(1 \cdot / r)$ & rqVY $(I F / I)$ & $\operatorname{rF\Delta \Delta ~(19/1)}$ & rafa $(19 / 4)$ & ravr $(19 / 4)$ & $r \cdot-r q$ \\
\hline $1 F 91(9 / 1)$ & $\operatorname{lV} 19(N / 1)$ & r. Qr (q/V) & rYOD (1.) & $r r \Delta \Delta(9 / 9)$ & $p \cdot-p q$ \\
\hline $1 \cdots r(F / 1)$ & $1190(\Delta / \Delta)$ & IFFD (G/V) & $1 \Delta \Delta \Delta(9 / 9)$ & $199 V(9 / 1)$ & $\Delta \cdot-\Delta q$ \\
\hline$\Delta I V(Y / I)$ & $\operatorname{gkr}(\boldsymbol{r})$ & $199(f)$ & $\Lambda \Delta \mathcal{S}(\Gamma / \Lambda)$ & $\operatorname{AVV}(\mathbf{r} / 9)$ & $9 \cdot-99$ \\
\hline$\Delta r(\cdot / 9)$ & If. $(\cdot / \mathrm{V})$ & FヘY $(Y / Y)$ & $\Delta 1 \Lambda(Y / Y)$ & $\Delta \wedge I(Y / F)$ & $r \cdot-v q$ \\
\hline \multirow[t]{2}{*}{$\Delta r(\cdot / r)$} & $\Delta \Delta(\cdot / \Gamma)$ & rrg $(1 / 1)$ & $Y \& \mid(1 / Y)$ & rVq $(1 / 1)$ & بيش از •م سال \\
\hline & & & & & جنس \\
\hline $19 \mathrm{~V} 99(9 N / \Gamma)$ & IFYGY (GV/F) & IFVGD (GN/A) & 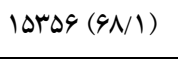 & $191 \mathrm{Yq}(9 / / 4)$ & مرد \\
\hline \multirow[t]{2}{*}{ VAIr (rI/V) } & $9 \wedge \pi r(r Y / F)$ & $G V \cdot r(r M / Y)$ & $V Y \cdot 1 \quad(Y Y / Q)$ & $W V \cdot(r / / 9)$ & زن \\
\hline & & & & & منطقه حادثه \\
\hline । १४৭४ (VN/A) & $10990(V F / F)$ & IDMMF (VF) & IFAV9 (99) & $19 \Delta 94(9 V / T)$ & شهر \\
\hline
\end{tabular}

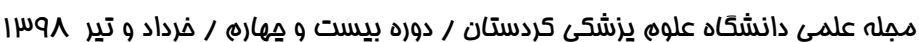


4عا براسى (وند ايِيديدولوزَيك...

\begin{tabular}{|c|c|c|c|c|c|}
\hline $\operatorname{rol\Lambda }(1 \cdot / r)$ & $r \cdot 9 V(9 / 9)$ & YFVT $(11 / \Delta)$ & rAY $(19 / 9)$ & MrAF (IT/A) & روستا \\
\hline \multirow[t]{2}{*}{$\operatorname{rgqF}(1 \cdot / 9)$} & $r \mu \cdot r(1 \Delta / V)$ & $\mu \| \cdot(\mid F / \Delta)$ & $\operatorname{r\Delta \Delta V}(I V / I)$ & $1901(1 N / 9)$ & خارج از شهر و روستا \\
\hline & & & & & نوع حادثه \\
\hline $\operatorname{Irr}(\Delta)$ & $\mathrm{VAV}(\mathrm{r} / \mathrm{V})$ & $1 \cdot V Y(\Delta)$ & $V \notin q(r / \Gamma)$ & $9 \Delta \Delta(Y / V)$ & عابر يياده \\
\hline $\operatorname{rr\Delta T}(\mathbf{Q} / \mathrm{Y})$ & $1.99(\Delta / Y)$ & $10 \Delta \Delta(V / Y)$ & $1499(9 / 9)$ & $\operatorname{lrq9}(\Delta / \Gamma)$ & تصادف موتورسوار \\
\hline FATG (I9/V) & $\Delta r q q(Y \Delta / 9)$ & $F Y V \cdot(19 / 9)$ & $\operatorname{F\Delta qr}(Y \cdot / r)$ & $\Delta F G Y(Y Y / Y)$ & تصادف خودرو \\
\hline FF^G (IN/Y) & 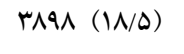 & FFVI $(Y \cdot / \Lambda)$ & HFVq $(1 \Delta / F)$ & $\operatorname{rogr}(\mid F / \Delta)$ & سقوط \\
\hline $1499(9)$ & $(r) .9(1)$. & $4 \cdot v 9(19)$ & $9191(Y V / T)$ & $\operatorname{VQFF}(r \cdot / V)$ & ضربه \\
\hline FAT $(Y)$ & $\Delta / F(T / F)$ & $F F D(Y / I)$ & $\operatorname{MFV}(1 / \Delta)$ & $\operatorname{rVV}(1 / 1)$ & حمله حيوانات \\
\hline $1 r q \cdot(\Delta / r)$ & $a r v(F / F)$ & $V F \mid(r / \Delta)$ & $\| Y Y(\Delta)$ & $\operatorname{l\Delta qF}(9 / 0)$ & مسموميت \\
\hline$V 4(\cdot / r)$ & $\Lambda \vee(\cdot / f)$ & $9 \Lambda(\cdot / r)$ & $q \pi(\cdot / r)$ & $94(\cdot / \pi)$ & برق برفتكى \\
\hline$\Delta r r(Y / l)$ & rma (1/9) & $\operatorname{rrV}(1 / 9)$ & $\operatorname{MYF}(1 / F)$ & FYF (I/V) & عقرب و مارگزيدگى \\
\hline IVDF $(V / I)$ & $14.9(9 / V)$ & $r \cdot r(1 / F)$ & rVF (I/V) & fIf $(I / V)$ & سوختكى \\
\hline$\Delta G \cdot(Y / \Gamma)$ & $\mathrm{rr} \cdot(1 / \Delta)$ & $|r \wedge|(G / F)$ & Irro (D/Q) & $11 \% V(F / 9)$ & خشونت \\
\hline $11.4(F / \Delta)$ & $r .9 V(9 / \Lambda)$ & $19 V Y(9 / Y)$ & $1 . .9(F / \Delta)$ & $9.9(T / 0)$ & خود كشى \\
\hline If $(\cdot / 1)$ & If $(\cdot / 1)$ & $1 \cdot(\cdot / \cdot 9)$ & $11(\cdot / 1)$ & $9(\cdot / \cdot 9)$ & غرقشدىى \\
\hline \multirow[t]{2}{*}{ FAYA (IN/F) } & $\operatorname{rIrr}(1 \cdot / I f)$ & VAT $(r / 9)$ & $|f q|(9 / 9)$ & IDFA $(\varepsilon / \Gamma)$ & ساير \\
\hline & & & & & 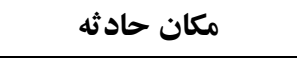 \\
\hline GFOF $(Y G / Y)$ & $\Delta \Delta r r(Y G / Y)$ & $\operatorname{AV\Lambda \Lambda }(F \cdot / q)$ & NITD (rq) & $Q 9 \cdot \Gamma(\mu q)$ & منزل \\
\hline rYAV $(I T / F)$ & raYA $(1 Y / 9)$ & DIrA (Yr/Q & $\Delta Y \Delta V(Y r / T)$ & $4 \wedge \ldots(19 / \Delta)$ & كوجه و خيابان \\
\hline $\operatorname{rakT}(\mid F / \Lambda)$ & $r F \mid \cdot(19 / r)$ & ragF (IN/D) & $\operatorname{raVr}(Y \cdot / r)$ & $\Delta \Delta Y \Delta(Y Y / \Delta)$ & بزر اهر اه و جاده \\
\hline VA $(\cdot / r)$ & $\operatorname{Vq}(\cdot / \mathbb{F})$ & $F \Delta q(Y / 1)$ & $r V r(I / V)$ & rVA $(1 / 1)$ & مدرسه، مكان آموزشى \\
\hline $1 \cdot V r(F / f)$ & $\wedge q \cdot(\boldsymbol{F} / \mathrm{r})$ & l9rv (9) & $\operatorname{rMT}(1 \cdot / r)$ & $r V H F(11 / 1)$ & محل كار \\
\hline $4 \cdot \Delta(Y / F)$ & $V \Delta(\cdot / f)$ & $F F I(Y / I)$ & $\Lambda r q(r / V)$ & $\operatorname{VAr}(r / Y)$ & اماكن ورزشى، تفريحى \\
\hline $\operatorname{Fir}(1 / \mathrm{V})$ & $F \cdot r(Y)$ & $\operatorname{rAV}(1 / \Lambda)$ & FFG (Y) & $\Delta r \cdot(r / l)$ & اماكن عمومى \\
\hline Vq $(\cdot / \mathrm{V})$ & $V \Delta(\cdot / \mathcal{F})$ & irs $(\cdot / 9)$ & Yq. $(1 / Y)$ & $\operatorname{rr}(\cdot / 1)$ & 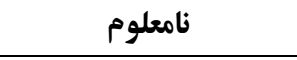 \\
\hline QFAD (rN/D) & WVI (r\&/A) & $F \Delta Q(Y / I)$ & $\operatorname{rAr}(I / \mathrm{V})$ & $\operatorname{Mr\Delta }(1 / \mathcal{F})$ & ساير \\
\hline rFq. P & $r 1 \cdot 90$ & rIFEY & rraDr & TFDQq & كل \\
\hline
\end{tabular}




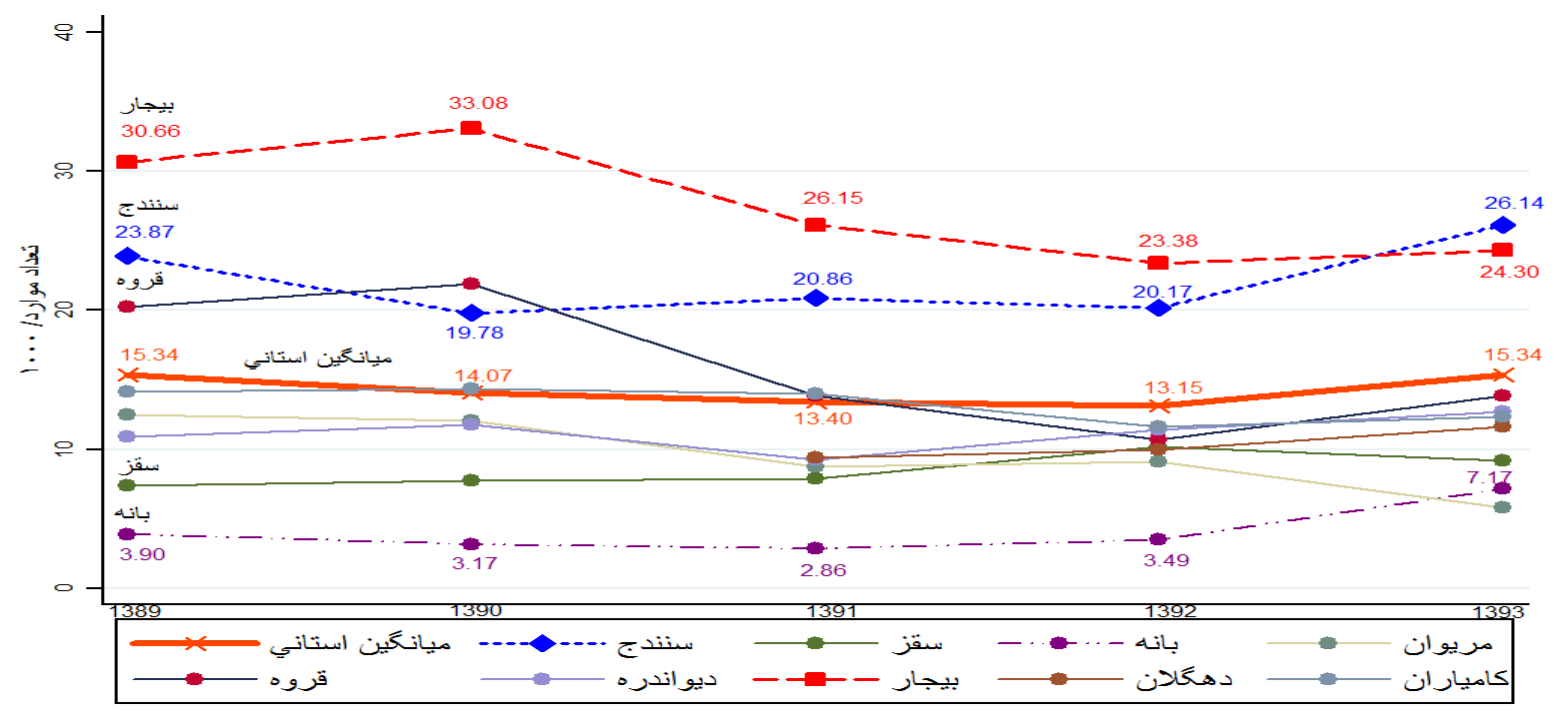

نمودار 1 :روند بروز حوادث و سوانح در استان كردستان (جمعيت استاندارد سرشمارى سال هوس|)

از نظر روند سوانح و حوادث در شهرستان هاى استان كردستان موارد بروز بررسى شد. در مطالعه عليزاده و همكاران نشان داده شد روند زمانى سوانح و حوادث

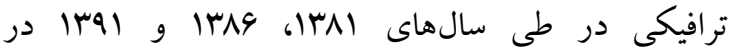
استانهاى مختلف ايران متفاوت بود و بيشترين موارد مركى

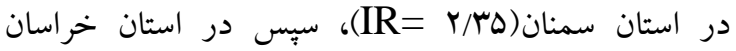
شمالى (IR=Y/YV) ديده شد (TI). در مطالعه سايه ميرى و همكاران نيز نشان داده شد بيشترين ميزان بروز خودكشى در

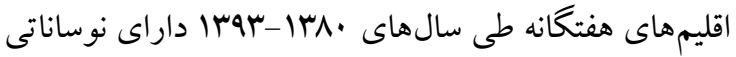
بود. در مناطق مورد بررسى بيشترين و كمترين ميزان بروز خودكشى موفق به ترتيب در منطقه ا (ايلام، كرمانشاه،

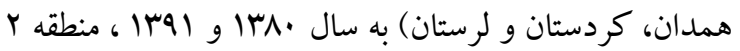
(آذربايجان غربى، آذربايجان شرقى، اردبيل، مركزى،

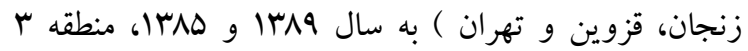

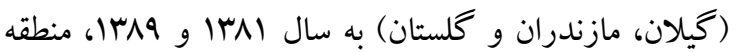
F(خراسان شمالى، خراسان رضوى، خراسان جنوبى ، كرمان

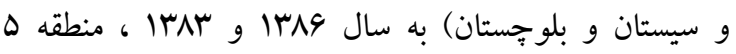

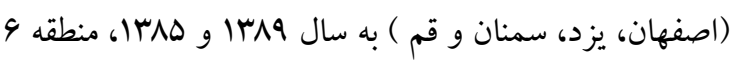

بررسى روند حوادث و سوانح در كل استان نشان مىدهد كه

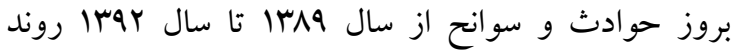

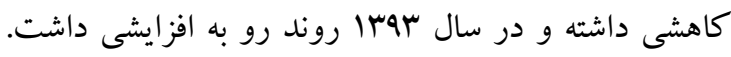
اين افزايش روند ممكن است به علت افزايش جمعيت در معرض خطر، بهبود سيستم هاى ثبت حوادث و يا افزايش واقعى حوادث و سوانح باشد (11). از نظر روند حوادث و سوانح در شهرستانهاى مختلف

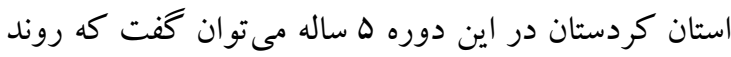

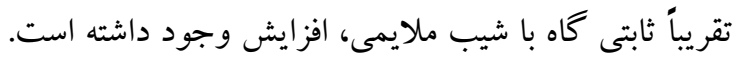

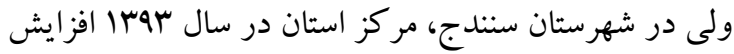
قابلتوجهى در آمار حوادث و سوانح ديده مى شود. بهطور كلى تغييرات در روند بروز سوانح و حوادث و بخصوص سوانح ترافيكى ممكن است به علت فاكتورهاى جغر افيايى، هزينه وايين بنزين، سيستم حمل و نقل عمومى ضعيف، رشد زياد صنعت خودروسازى و كيفيت پايين اتومبيل ها و تجهيزات موتورسيكلت ها، همجنين شبكه هاى جاده اى نامن در منطقه مورد نظر باشد (Y I). 
نتايج مطالعه حاضر نشان داد حوادث و سوانح در مردان

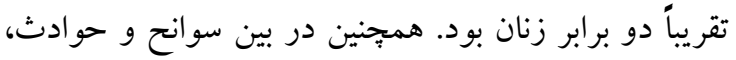
تصادفات بيشترين سانحه را به خود اختصاص داده است كه

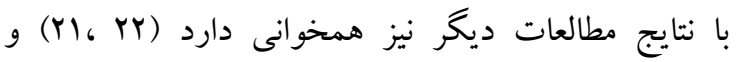

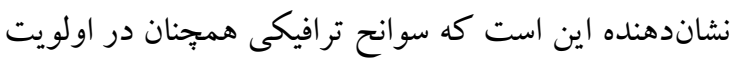

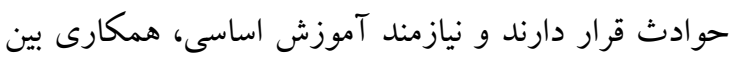
بخشى مستمر و قدرتمند و در برخى موارد اعمال محدوديتها و قوانين توسط يُليس راهور است مشاهده شد (YT)

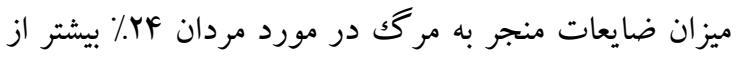

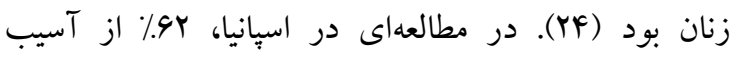

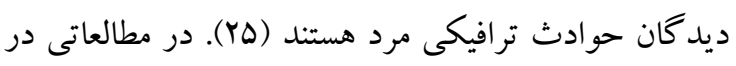
تركيه حوادث مربوط به مردان (9/V/V) بيشتر از زنان

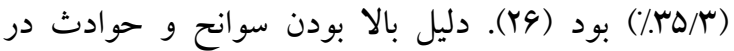
مردان نسبت به زنان، بيشتر انجام دادن رفتارهاى برخطر در مردان در مقايسه با زنان است. مطالعات قبلى نشان دادهاند رفتارهايى مانند سرعت غيرمجاز، استفاده نامناسب از وسايل نقليه، عبور از مناطق غيرمجاز، استفاده ناكافى از وسايل ايمنى را مى توان نام برد (·r, (19).

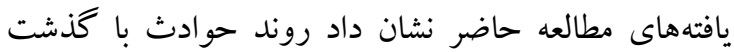
زمان به سمت محل وقوع در شهر افزايش داشته است كه با توجه به افزايش جمعيت، درصد سالانه در استان و با توجه به اينكه روستائيان استان نيز براى رفع و رجوع امور امور روزانهان به شهر مراجعه مى كنند، قابل توجيه است. در مطالعه عبدالوند و همكاران (YN) و موسى زاده و همكاران (Y9) بيشترين حوادث در مناطق شهرى ديده شد با نتايج مطالعه حاضر نيز همخوانى داشت. در توجيه اين امر مىتوان به رعايت نكردن قوانين راهنمايى و رانندگىى، استفاده بيشتر افراد از وسايل نقليه شخصى و سرعت غيرمجاز اشاره كرد.

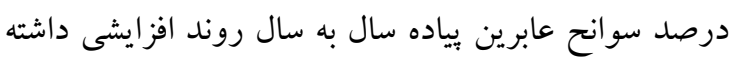

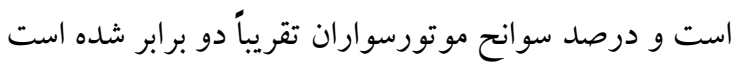

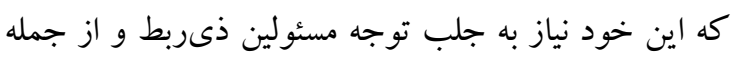

(جهارمحال و بختيارى، كهخيلويه و بويراحمد و

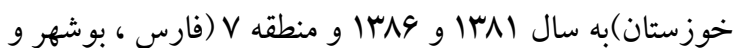
هرمز كان) به سال سربار و •وسا تعلق داشت (IF).

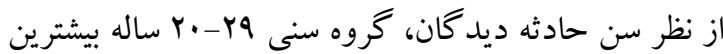
آمار حوادث را داشتند. فقط در سال سهسا گروه سنى كمتر

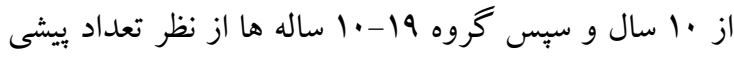
كرفته است. در مطالعه مقطعى خزائى و همكاران كه در فاصلهى زمانى MMM|-rM I در استان همدان بر روى نتاج

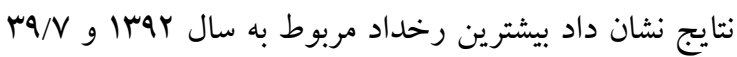

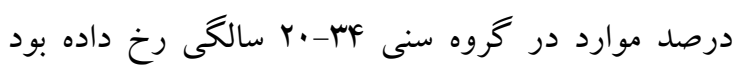

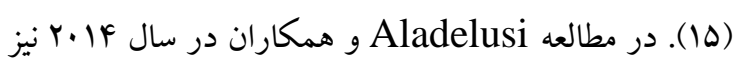

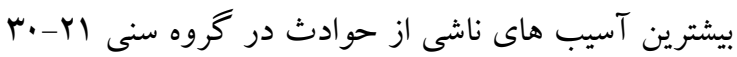

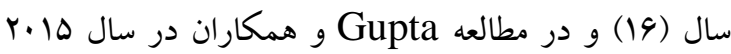
متوسط سن افراد آسيب ديده Zimmerman ترافيكى در تانزانيا در سال ها بr انجام شد نتايج نشان داد

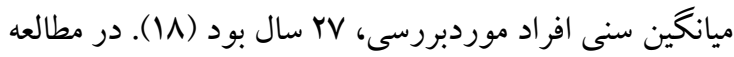
مقطعى قائم و همكاران كه بر روى ·ANF نفر از عابرين يياده سانحه ديده در فاصله زمانى

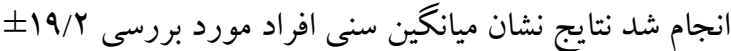
F F أF سال بود (19). در مطالعه ديخرى كه توسط قائم و همكاران در استان فارس بر روى سمابا نفر از افراد دجار

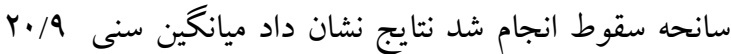
FF/AVI

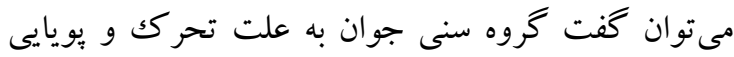
بيشتر در معرض خطر بيشتر سوانح ترافيكى مختلف قرار

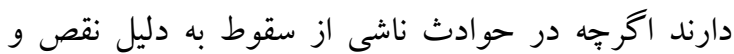
كاهش فعاليت فيزيكى، كاهش ظرفيت شناختى مؤثر و ابتلاى افراد به بيمارىهاى مزمن متعلدد، ميانكين سنى افراد

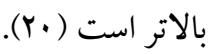


بهور كلى نوسانات ايجاد شده در روند بروز خود كشى مى تواند ناشى از تأثير عوامل بيولوزيك، محيطى، روانى و اجتماعى طى سالهاى مذكور باشد. سوانح و حوادث علل مشخص و گوناگون دارند و ييشخيرى از آنها مستلزم شناخت و توجه به ابعاد مختلف شبكه عليتى و همكارى بين بخشى كليه سازمانهاى درگير است. به

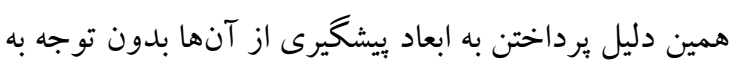

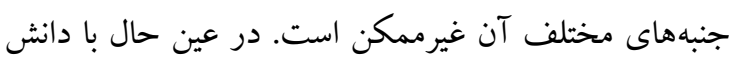
كنونى بشر، اكثريت حوادث و مسموميتها قابل كنترل و بيشخيرى هستند و اين مهم تنها با حمايت، مساعدت و همكارى بين بخشى ميسر خو اهد شد.

\section{نتيجه كيرى}

در نظر داشتن اين مشكل در تصميم گيرىهاى مناسب براى برنامه ريزى و انجام مداخلات مؤثر در كاهش سوانح و حوادث بسيار مهم است. همجنين، طراحى و انجام يزّوهشهاى دامنهدار، به ويزه درباره تأثير مسائل روانى كه ارتباط تنگاتنگى با خودكشى دارد براى شناسايى علل مرتبط با خود كشى ضرورى و مهم به نظر مىرسد.

\section{تشكر و قدردانى}

اين مطالعه، قسمتى از نتيجه بيايان نامه دانشجويى بزشكى

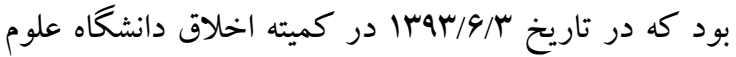
يزشكى كردستان با كد معاونت محترم تحقيقات و فن آورى دانشگاه علوم يزشكى كردستان و دانشكده بزشكى به عنوان حمايت كننده مالى و همجنين كميته تحقيقات دانشجويى، كاركنان محترم معاونت بهداشتى استان كردستان و مركز تحقيقات بالينى بيمارستان كوثر سنندج كه ما را در انجام اين تحقيق يارى نمودند تقدير و تشكر به عمل مى آيد.
يليس راهنمايى و رانندگى كه بايد با اجراى دقيق تر قوانين و مقررات مربوط به موتورسواران به اين مسئله اهميت در خور توجه خود را بدهند. اين درصد در مطالعه قائم و

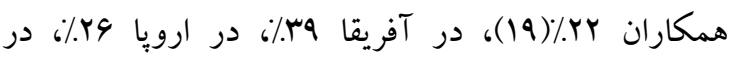

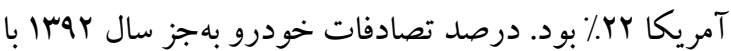
شيبى ملايم روند كاهشى داشته است ( •r). در مورد ضربه، نكته قابل توجه اين است كه در اين ه ساله روند كاهشى شديدى داشته است. به طورى كه از بالاى

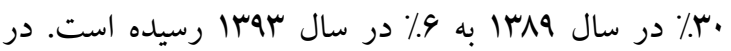
مطالعه خزايى و همكاران از نظر نوع حادثه بيشترين حوادث به ترتيب ضربه (Y/Y/Y/)، تصادف خودرويى (YI/Y)، تصادف موتورسوار (9/9٪) بود (1) (1). بر اساس يافتهاى مطالعه حاضر، اقدام به خودكشى از سال 91 تا ب9 روند افزايشى تا حد Fُ برابر داشته است، اما در سال به فرو كث كرده است. Rock و همكاران كه بر دادههاى خودكشى در سالهاى ·19V تا 1999 انجام شده بود، نشان داد افزايش خود كشى طى زمان غالباً همسو با افزايش روند استفاده از روشهاى خشن و همجينين، ازدياد خود كشى در مردان بوده است (اس) در مطالعه دليرى و همكاران، روند بروز خود كشى بهصورت دونمايى بوده بهطورى كه در سال . داراى كمترين ميزان بود و نشان دادند درمجموع بروز خود كشى در ايران طى دهه هشتاد روند كاهشى داشت (If). خطر خودكشى براى كسانى كه اخيراً تحت درمان روانيزشكى بودهاند، به ويزه بيماران با اختلال افسردگى، بركي، اضطراب و اسكيزوفرنى بالا است. عواملى مانند سابقه

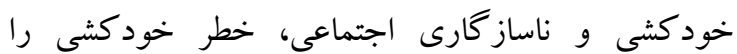
افزايش مىدهند. بهطوركلى اختلالات روانى، يِيشبينى كننده اقدام به خود كشى هستند و همجينين عوامل مرتبط با بال خود كشى مثل وضعيت تأهل، افسردكى، مصرف مواد و سن نوجوانى، افزايش دهنده خطر خودكشى مىباشند (Yr).

\section{References}


1. Bonilla-Escobar FJ, Gutiérrez MI. Injuries are not accidents: towards a culture of prevention. Colombia Medica 2014;45:132-5.

2. World Health Organization. Global status report on road safety 2013: supporting a decade of action: summary. World Health Organization; 2013.

3. Ballesteros MF, Williams DD, Mack KA, Simon TR, Sleet DA. The Epidemiology of unintentional and violence-related injury morbidity and mortality among children and adolescents in the united states. Int J Environ Res Public Health 2018;15:616.

4. World Health Organization. The world health report 2002: reducing risks, promoting healthy life. World Health Organization; 2002.

5. Garg N, Hyder AA. Exploring the relationship between development and road traffic injuries: a case study from India. Eur J Public Health 2006;16:487-9.

6. Wickramanayake I, Gunasena G, Wickramanayake H, Goonasekera C. The Prevalence of known risk factors for road traffic accidents (RTA) in kandy police administrative area. BMSED 2007;12:129-31.

7. Bahadorimonfared A, Soori H, Mehrabi Y, Delpisheh A, Esmaili A, Salehi M, et al. Trends of fatal road traffic injuries in Iran (2004-2011). PloS One 2013;8:e65198.

8. Moradi A, Rahmani K. Trend of traffic accidents and fatalities in iran over 20 years (19932013). J Mazandaran Univ Med Sci 2014;24:223-34. [In Persian]

9. Kanchan T, Kulkarni V, Bakkannavar SM, Kumar N, Unnikrishnan B. Analysis of fatal road traffic accidents in a coastal township of South India. J Forensic Leg Med 2012;19:44851 .

10. Kopits E, Cropper M. Traffic fatalities and economic growth. Accid Anal Prev 2003;37:169-78.

11. Neghab M, Habibi M, Rajaeifard A, Choubineh A. Home accidents in Shiraz during a 3year period (2000-2002). JKUMS (Behbood) 2008;11:428-40. [In Persian]

12. Naghavi M, Shahraz S, Bhalla K, Jafari N, Pourmalek F, Bartels D ,et al. Adverse health outcomes of road traffic injuries in Iran after rapid motorization. Arch Iran Med 2009;12:28494.

13. Alizadeh A, Zare M, Darparesh M, Mohseni S, Soleimani-Ahmadi M. GIS based analysis of Intercity Fatal Road Traffic Accidents in Iran. J Med Life 2015;8:77-82.

14. Daliri S, Bazyar J, Sayehmiri K, Delpisheh A, Sayehmiri F. Investigation of the incidence rate of suicide in iran during years 2001-2014 a systematic review and meta-analysis study. SSU Journals 2016;24:757-68.

15. Khazaei S, Mazharmanesh S, Khazaei Z, Goodarzi E, Mirmoini R, MohammadianHafshejani A, et al. An epidemiological study on the incidence of accidents in the Hamadan province during 2009 to 2014. PSJ. 2016;14:8-16. [In Persian]

16. Akinmoladun TAI, Olusanya O, Fasola A. Evaluation of pedestrian road traffic maxillof acial injuries in a Nigerian tertiary hospital. Afr J Med Med Sci 2014;43:353-9.

17. Gupta S, Wong EG, Nepal S, Shrestha S, Kushner AL, Nwomeh BC, et al. Injury prevalence and causality in developing nations: results from a countrywide population-based survey in Nepal. Surgery 2015;157:843-9.

18. Zimmerman K, Jinadasa D, Maegga B, Guerrero A. Road traffic injury on rural roads in Tanzania: measuring the effectiveness of a road safety program. Traffic Inj Prev 2015;16:45660.

19. Ghaem H, Soltani M, Yadollahi M, ValadBeigi T, Fakherpour A. Epidemiology and outcome determinants of pedestrian injuries in a level I trauma center in southern Iran; a cross-sectional study. Bull Emerg Trauma 2017;5:273-9. 
20. Ghaem H, Soltani M, Yadollahi M, Abdollahi M. An epidemiological study of accidents and incidents in fall victims referring to Shahid Rajaee hospital, Shiraz, 2009-2014. Trauma Monthly. Trauma Monthly 2018;23:1-8.

21. Soori H, Akbari E, Ainy A, Zali M, Naghavi S. Epidemiological pattern of non-fatal injuries in Iran. Pak J Med Sci 2010;26:206-11.

22. Esmaeili Z, Vaezzadeh N. The pattern of injuries in children under 15 years of Mazandaran. MUMS 2000;10:1-6. [In Persian]

23. Soodejani M, Shirani Faradonbeh R, Hashemi S, Zahedi A, Dehghani A. Epidemiology of accidents and injuries in the city of Lordegan in 2012: A Short report. JRUMS. 2015;13:91722. [In Persian]

24. Ganveer G, Tiwari R. Injury pattern among non-fatal road traffic accident cases: a crosssectional study in Central India. Indian J Med Sci 2005;59:23-30.

25. Sözüer M, Yildirim C, Senol V, Unalan D, Naçar M, Günay O. Risk factors in traffic accidents. Ulusal travma dergisi. TJTES 2000;6:237-40.

26. Esiyok B, Korkusuz I, Canturk G, Alkan HA, Karaman AG, Hamit Hanci I. Road traffic accidents and disability: A cross-section study from Turkey. Disability and Rehabilitation. 2005;27:1333-8.

27. Karbakhsh M, Rostami G, Zargar M. Factors influencing the severity of injuries in motor vehicle crashes. Payesh 2004;3:273-8. [In Persian]

28. Abdolvand M, Monfared AB, Khodakarim S, Farsar A, Golmohammadi A, Safaei A. Evaluation of accidents and incidents at injury registered in medical centers affiliated to Shahid Beheshti university of medical sciences (2012-2013). Safety Promot Inj Prev (Tehran) 2014;2:65-72.

29. Moosazadeh M, Nasehi MM, Mirzajani M, Bahrami MA. Epidemiological study of traumatic injuries in emergency departments of Mazandaran hospitals, 2010. J Mazand Univ Med Sci 2013;23:144-54.

30. Martin JL, Wu D. Pedestrian fatality and impact speed squared: cloglog modeling from French national data. Traffic Inj Prev 2018;19:94-101.

31. Rock D, Greenberg DM, Hallmayer JF. Increasing seasonality of suicide in Australia 1970-1999. Psychiatry Res 2003;120: 43-51.

32. Zare H, Nazer M, Sayyadi AR. Frequency of mental disorders and factors related to suicide in patients referring to emergency ward of Ali Ebne Abitaleb hospital of Rafsanjan in 2007. JRUMS 2010;9:221-32. [In Persian] 